\title{
Change of Spectral Analysis of Fetal Heart Rate During Clinical Hypnosis: a Prospective Randomised Trial from the 20th Week of Gestation Till Term
}

Spektralanalyse der fetalen Herzrate unter klinischer Hypnose:

eine prospektiv randomisierte Studie von der 20. Schwangerschaftswoche bis zum Entbindungstermin

Authors

Affiliations
J. Reinhard ${ }^{1}$, B. R. Hayes-Gill ${ }^{2}$, S. Schiermeier ${ }^{3}$, W. Hatzmann ${ }^{3}$, T. M. Heinrich ${ }^{1}$, H. Hüsken-Janßen ${ }^{4}$, E. Herrmann ${ }^{5}$, F. Louwen ${ }^{1}$

The affiliations are listed at the end of the article

\section{Key words \\ - Fetal heart monitoring \\ - spectral analysis \\ - frequency analysis \\ - heart rate variability \\ - clinical hypnosis}

Schlüsselwörter

- fetale Herzfrequenzüberwachung

- Spektralanalyse

- Frequenzanalyse

- Herzfrequenzvariabilität

- Hypnose/Hypnotherapie received 14.9.2011

revised $\quad 31.1 .2012$

accepted 28.2.2012

Bibliography

DOI http://dx.doi.org/

10.1055/s-0031-1298399

Geburtsh Frauenheilk 2012; 72:

316-321 ๑ Georg Thieme

Verlag KG Stuttgart · New York .

ISSN 0016-5751

Correspondence

Priv.-Doz. Dr. Joscha Reinhard,

MBBS BSC (Hon)

Johann Wolfgang Goethe

University Frankfurt

Obstetrics and Gynaecology

Department

Theodor-Stern-Kai 7

60590 Frankfurt

joscha.reinhard@kgu.de

\section{Abstract}

$\nabla$

Objective: To investigate the functional adaptive process of the fetal autonomic nervous system during hypnosis from the 20th week of gestation till term. Are there changes in the power spectrum analysis of fetal heart rate when the mother is having a clinical hypnosis or control period? Study Design: Fourty-nine FHR recordings were analysed. Included recordings were from singletons and abdominal fetal ECG-monitored pregnancies. All women were randomised to receive clinical hypnosis followed by a period with no intervention or vice versa. Statistical analyses were performed with the Wilcoxon signed ranks and Spearman rho correlation tests.

Results: There was a significant difference found between fetal heart rate at baseline $(144.3 \pm 6.0)$ and hypnosis $(142.1 \pm 6.4)$. A difference was also detected between the standard deviation of the heart rate between baseline $(6.7 \pm 1.9)$ and hypnosis $(6.8 \pm 3.5)$. LFnu was smaller during baseline $(80.2 \pm 5.3)$ than during hypnosis $(82.1 \pm 5.7)$, whereas HFnu was significantly larger $(19.8 \pm 5.3$ vs. $17.9 \pm 5.7$ ). There was no correlation between the gestation age and the change in LFnu, HFnu or ratio $\mathrm{LF} / \mathrm{HF}$ due to the hypnosis intervention. Conclusion: The functional adaptive process of the fetal autonomic system during hypnosis is reflected by a sympathovagal shift towards increased sympathetic modulation.

\section{Zusammenfassung \\ $\nabla$}

Fragestellung: In der vorliegenden Studie sollte überprüft werden, wie das autonome Nervensystem auf eine Hypnoseintervention zwischen der 20. Schwangerschaftswoche bis zum Entbindungstermin reagiert. Gibt es einen Unterschied der Spektralanalyse der fetalen Herzfrequenz, wenn die werdende Mutter eine Hypnoseintervention erhält im Vergleich mit der Kontrollperiode ohne Intervention?

Studiendesign: 49 Einlingsschwangerschaften mit abdominaler fetaler EKG-Ableitung wurden analysiert. Alle Schwangeren wurden randomisiert, um eine Hypnoseintervention und eine Kontrollperiode oder vice versa zu erhalten. Zur statistischen Analyse wurden der WilcoxonSigned-Rank-Test und der Spearman-Rho-Korrelationstest herangezogen.

Ergebnisse: Es ergab sich eine statistisch signifikante Differenz zwischen der fetalen Herzfrequenz zwischen Kontrollphase $(144,3 \pm 6,0)$ und der Hypnoseintervention $(142,1 \pm 6,4)$, sowie in der Standard-Deviation der Kontrollphase (6,7 \pm $1,9)$ und der Hypnoseintervention $(6,8 \pm 3,5)$. LFnu war niedriger in der Kontrollphase $(80,2 \pm$ $5,3)$ als während der Hypnoseintervention $(82,1$ $\pm 5,7$ ), wohingegen HFnu statistisch signifikant größer war (19,8 $\pm 5,3$ vs. 17,9 $\pm 5,7)$. Es gab keine Korrelation zwischen dem Gestationsalter und einer Änderung der LFnu, HFnu oder LF/HF während der Hypnoseintervention.

Schlussfolgerung: Das fetale autonome Nervensystem reagiert bei einer mütterlichen Hypnoseintervention durch einen sympathovagalen Shift in der Richtung eines erhöhten Sympathikotonus. 


\section{Introduction}

\section{$\nabla$}

Hypnosis is a recognised psychological technique [1], which is characterised by deep relaxation, focused attention, vivid imagery and increased receptivity to suggestion [2]. Functional brain imaging $[3,4]$ and EEG studies $[5,6]$ showed that the hypnotic state is different from sleep, from alert awareness and relaxed rest. The hypnotisability varies from person to person, but is higher during pregnancy [7]. The ability to influence and access function beyond conscious control is increased during the hypnotic state $[8,9]$, which might proof beneficial in preterm labour [10-12] and might be able to influence the blood flow of the A. umbilicalis [13].

The autonomic nervous system is altered during hypnosis which includes acute [14] and chronic [15,16] (after hypnotherapy) changes. Heart rate variability (HRV) provides a tool to evaluate acute cardiac autonomic alterations during hypnosis [17]. The changes of the autonomic nervous system (ANS) can be studied using spectral analysis of fetal heart rate (FHR) periods. In human adults frequency bands have been identified that can indicate the sympathetic and parasympathetic nervous system input $[18,19]$. The high frequency (HF) component is mainly indicating parasympathetic nervous system, whereas a combined sympathetic and parasympathetic nervous system is reflected by the low frequency (LF) components [19]. The sympathovagal balance can be evaluated using the ratio between LF and HF [19]. Due to maturation of the fetal autonomic nervous system the absolute LF and HF power increases as pregnancy progresses $[20,21]$. In the third trimester the increase in LF and HF power is not so high [21]. Furthermore typical reflex responses of the parasympathetic nervous system only begin at term and reach adult levels after birth [22]. Fetal LF and HF bands are influenced by the behavioural state [23], but results of our study group also showed an effect of fetal behavioural state depending on the state of the pregnant women [13,24].

Recently, a non-invasive abdominal fetal electrocardiogram (ECG), which provides true beat-to-beat evaluation with good signal quality [25-27], has been approved for clinical usage from the 20th week of gestation onwards.

To the best of our knowledge, no study has examined whether hypnosis influences fetal LF and HF bands during pregnancy.

\section{Materials and Methods \\ $\nabla$}

\section{Study samples}

All patients who had a single pregnancy were eligible to participate in this study. All (49/49) women who were informed about the study agreed to participate. None of the subjects had previous experience with hypnosis. None of the subjects had psychiatric or somatic symptoms and none had a history of cardiopulmonary, neurological, renal, psychiatric or other systemic disease. They were not using any drugs or medication. They were all nonsmokers. Exclusion criteria in our study were fetal malformations, fetal growth retardation and maternal diabetes mellitus. The gestation age of the women participating in the study is shown in Fig. 1. All women have now delivered healthy newborns. The study protocols were approved by the local ethics committee. In addition, all women gave written informed consent.

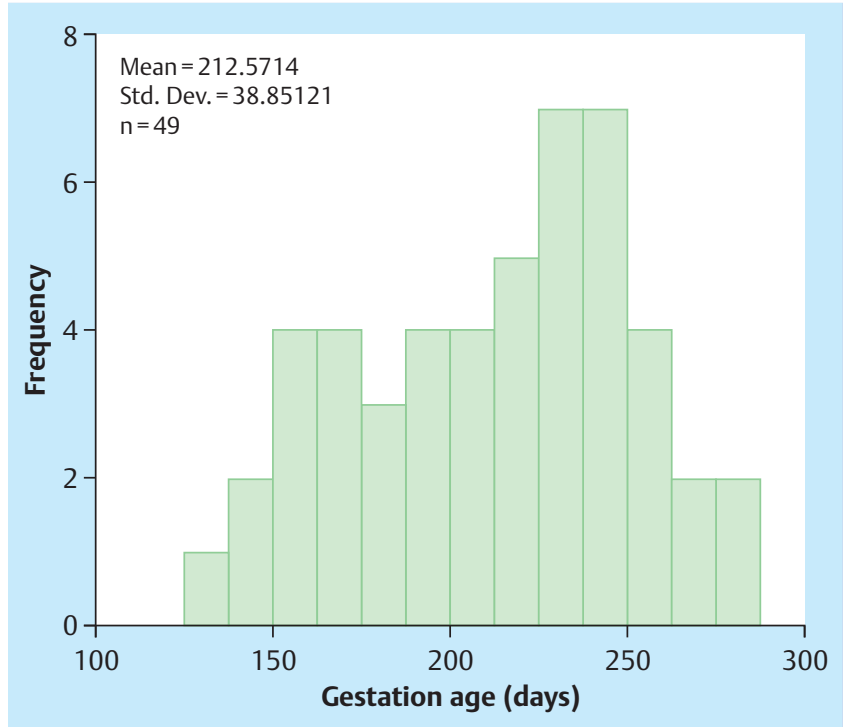

Fig. 1 Histogram of gestation age (days) $(n=49)$.

\section{Study protocol}

After ultrasound scan and preceded by a 10 -minute rest period, five Ambu VLC-00-S electrodes were placed on the maternal abdomen: one electrode was placed on the midline within a range of $2 \mathrm{~cm}$ above the navel or during the vernix period; this electrode's position was $6 \mathrm{~cm}$ above the navel or during early gestation the electrode was placed $1 \mathrm{~cm}$ below the fundus of the uterus; one was placed $6 \mathrm{~cm}$ above the symphysis, two were placed at the right and left lateral abdominal wall; and finally one reference electrode was placed towards the back on the right lateral of the abdomen. This configuration allows 3 parallel abdominal fetal ECG detection channels around the maternal abdomen. The skin was prepared for low impedance by gentle excoriation of the surface skin cells as described by the Monica protocol (using 3M Skinprep 2236). The electrodes were connected to the Monica AN24 recorder (Monica Healthcare, Nottingham, UK), and the signal was sampled at a frequency of $900 \mathrm{~Hz}$, thus giving a time resolution for the RR intervals of $0.9 \mathrm{~ms}$. Data were analysed offline after computer download. The Monica DK software was used to extract the beat-to-beat analysis, which uses a subtraction algorithm of the maternal ECG complex before detection of fetal ECG complexes (please see $\bullet$ Fig. 2). The consecutive RR intervals were exported and missing beats and pauses were filtered and replaced by an interpolated value using Kubios HRV Version 2.0. All time periods with at least 360 beats in the 3-minute record period, which correspond to a heart rate of at least 120 beats per minute, were evaluated in this study. Additionally, the following results were excluded if the average fetal heart rated dropped below 130 beats/min, which could cause aliasing of the respiratory frequency [20].

All recordings were carried out at Marien-Hospital Witten (tertiary care teaching hospital) and were selected consecutively from November 2009 till February 2010. The recording session consisted of two periods: (a) a baseline recording, with the instruction to keep the eyes open and relax. The subjects remained awake, did not speak, and were not disturbed; (b) a standard hypnotic test (Creative Imagination Scale) and a standard hypnotic induction, intervention and wakening $[28,29]$. Each period was randomly allocated for each subject. The clinical hypnosis inter- 


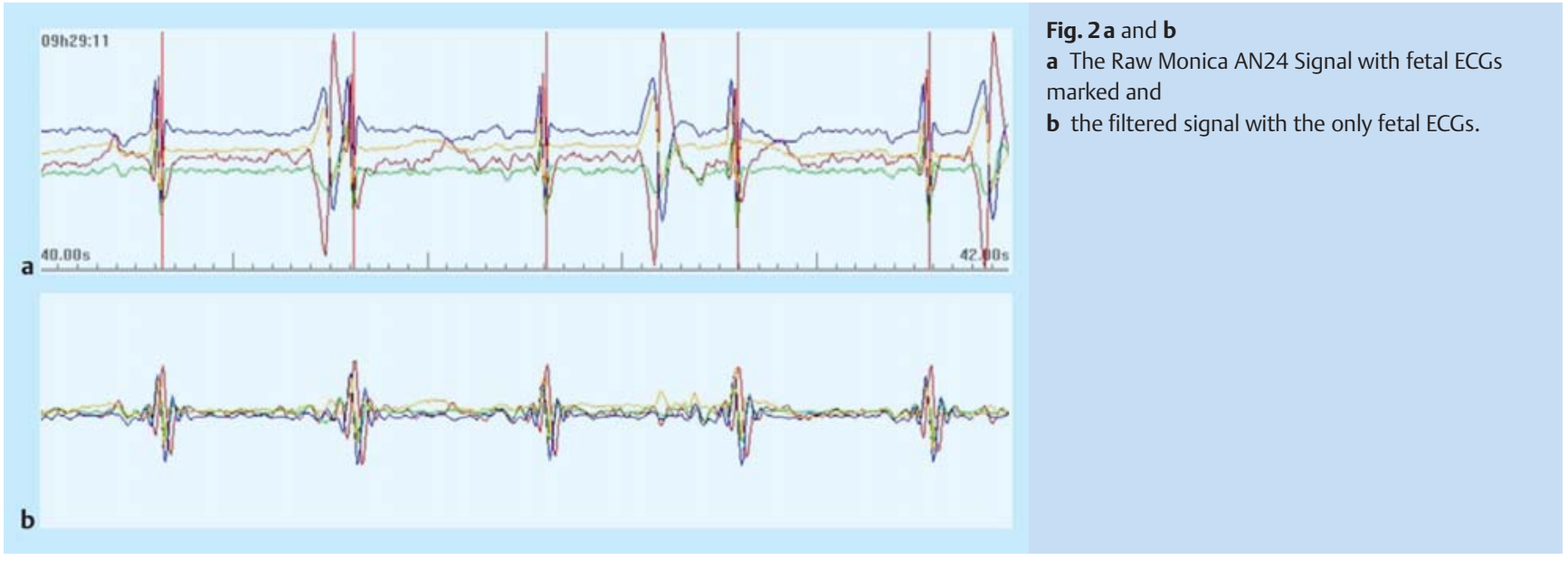

vention was carried out by the same trained hypnotherapist (J.R.).

\section{Data analysis}

Power spectral density

The methods used in this study are mainly based on the guidelines given in [30]. For each 3-minute recording period, data sets consisting of 256 points, overlapping by $50 \%$, were processed and power spectral density ( $\mathrm{ms} 2 / \mathrm{Hz}$ ) was then computed using a fast Fourier transform algorithm [31] (Kubios HRV Version 2.0). Total power was computed for a low frequency (LF) band from 0.04 to $0.15 \mathrm{~Hz}$ and a high frequency (HF) band from 0.15 to $0.4 \mathrm{~Hz}$ [30, 32]. Since large variation existed within the subjects, LF and HF are expressed in normalised units (nu) [33]: LFnu $=[\mathrm{LF} /(\mathrm{LF}+\mathrm{HF})$ $\times 100]$ and $\mathrm{HFnu}=[\mathrm{HF} /(\mathrm{LF}+\mathrm{HF})] \times 100$ and as a low-to-high ratio: LF/HF.

\section{Statistical methods}

All results are shown as mean values \pm standard deviation, median, quartiles and differences of the means. The Gaussian distribution of the differences between hypnosis and baseline measures was checked using the Q-Q-plots. If distributed normally, the paired t-test was used, otherwise the Wilcoxon signed rank test was applied. In order to test the hypothesis that the change in spectral frequency correlates with the gestational age of the fetus, the Spearman's rho correlation was calculated. The analyses were carried out using the SPSS Statistics 17.0 software (Scientific Packages for Social Sciences, Inc., Chicago, IL, USA). P $<0.05$ for a two-tailed test was considered statistically significant.

\section{Results \\ $\nabla$}

\section{Linear heart rate dynamics}

Fetal mean values and standard deviation for HRV parameters are presented in - Table 1. Q-Q-plot analysis showed that the fetal heart rate was distributed normally and a significant difference was found between baseline $(144.3 \pm 6.0)$ and hypnosis (142.1 \pm 6.4$)$. A difference was also detected between the standard deviation of the heart rate between baseline $(6.7 \pm 1.9)$ and hypnosis (6.8 \pm 3.5$)$. Fetal LFnu was smaller during baseline $(80.2 \pm 5.3)$ than during hypnosis $(82.1 \pm 5.7)$. Fetal HFnu was significantly larger $(19.8 \pm 5.3$ vs. $17.9 \pm 5.7)$ in control state compared to hypnosis ( Table 1 ). No statistically significant differ- ence was found using the fetal LF/HF ratio. There was no correlation between gestation age and the change in fetal LFnu, HFnu or $\mathrm{LF} / \mathrm{HF}$ ratio due to the hypnosis intervention.

A correlation was found between gestation age and fetal baseline heart rate $(\mathrm{r}=-0.40, \mathrm{p}=0.005)$, heart rate during hypnosis $(\mathrm{r}=0.45, \mathrm{p}=0.001)$, baseline standard deviation of the heart rate $(\mathrm{r}=0.47, \mathrm{p}=0.001)$ and standard deviation of the heart rate during hypnosis $(r=0.41, p=0.003)$. Gestation age also correlated with baseline LFnu $(r=0.38, p=0.008)$, HFnu $(r=0.38, p=0.008)$ and the LF/HF ratio $(r=0.35, p=0.014)$. No correlation was found between gestation age and fetal LFnu, HFnu and the LF/HF ratio during hypnosis.

\section{Non-linear heart rate dynamics}

No significant change was found for the fetal approximate entropy, Shannon entropy and sample entropy between baseline and hypnosis. Gestation age demonstrated a correlation with Shannon entropy $(r=0.11, p<0.001)$, sample entropy $(r=0.12$, $\mathrm{p}<0.001)$ and approximate entropy $(\mathrm{r}=0.15, \mathrm{p}<0.001)$. Fetal baseline LFnu and HFnu had a correlation with approximate entropy $(\mathrm{r}=-0.60, \mathrm{p}<0.001)$ and sample entropy $(\mathrm{r}=-0.64$, $\mathrm{p}<0.001$ ), but not with Shannon entropy. Fetal baseline LF/HF ratio similarly showed a correlation with approximate entropy $(\mathrm{r}=-0.68, \mathrm{p}<0.001)$ and sample entropy $(\mathrm{r}=-0.60, \mathrm{p}<0.001)$, but not Shannon entropy. During hypnosis fetal LFnu, HFnu and LF/HF ratio demonstrated no correlation with non-linear heart rate dynamics at all.

\section{Comments}

$\nabla$

The main finding of this study is a fetal change of heart rate, standard deviation of heart rate and a shift towards sympathetic dominance during hypnosis compared to relaxed rest. This was apparent both from a decrease in HFnu power, an increase in LFnu power and from an increase of the LF/HF ratio. Our results add new arguments that fetuses can react to external stimulus with changes of HRV much earlier than previously thought [22, 23].

\section{Heart rate}

Heart rate results showed that the heart rate is slightly lower with increased standard deviation during hypnosis. These results support previous studies, which indicate that the fetus is more 


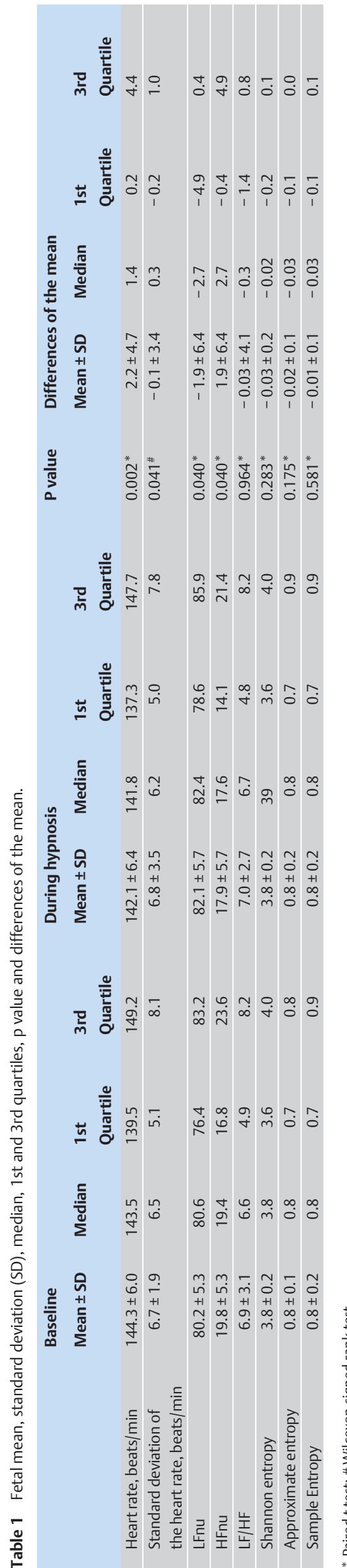

active during hypnosis [13]. Similar to previous studies [21,34], in our study fetal HRV changed with gestational age.

In adults, no conclusive results have been found whether hypnosis causes a decrease in heart rate [35-39].

\section{$H R V$ in the frequency domain}

To our knowledge no study has focused on fetal autonomic cardiovascular control during hypnosis. Several studies have described the development of the frequency power spectrum in the course of pregnancy $[40,41]$ or respiratory sinus arrhythmia $[42,43]$.

In adults, only a few studies have focused on autonomic cardiovascular control during hypnosis using HRV indices. The results showed conflicting results with $[36,44,45]$ and without $[46,47]$ change in parasympathetic activity. These discrepancies are most probably due to subtle differences in basal conditions, in HRV analysis, methodology in general (duration of different phases, free breathing or at a fixed frequency) and population selection (hypnotisability).

In our study increased fetal LFnu and decreased fetal HFnu can only be explained as secondary sympathetic reaction to the maternal hypnosis. In previous studies the increased fetal movements are consistent with this reaction to hypnosis $[13,24,48]$, rather than the expected parasympathetic reaction of the fetus of deep relaxation like the mother $[36,44,45]$.

\section{Non-linear heart rate dynamics}

Several studies demonstrated that non-linear dynamics also governs autonomic neural outflow [49-53]. In our collective only fetal approximate entropy was significant higher during hypnosis than the control period. Approximate entropy has also been used to demonstrate an increase of complexity in fetal heart rate during the course of pregnancy [54], which has also been shown in our study results.

\section{Study limitations}

Limitations of this study are that no evaluation for fetal respiration, which can influence the spectral analysis, has been done.

\section{Conclusions}

Our results indicate that the functional adaptive process of the fetal autonomic system during hypnosis is reflected by a sympathovagal shift towards increased sympathetic modulation, with a decreased heart rate and higher standard deviation. With the newly available, CE-certified non-invasive fetal abdominal ECG fetal changes in autonomic system can be analysed with true beat to beat evaluation.

\section{Contribution to Authorship}

All authors reviewed the results and wrote the article. The first author designed the study protocol, collected clinical data and carried out the hypnotic intervention. The first and second authors analysed the fetal heart rate data. 


\section{Funding}

$\nabla$

Source of financial support - We recieved 7000 Euro funding from Monica Health Care Ltd.

\section{Details of Ethics Approval}

$\nabla$

We received ethics approval of the "Ethik-Kommission der Medizinischen Fakultät der Ruhr-Unversität Bochum, Germany”, Reference No. 3358-08.

\section{Conflict of Interest \\ $\nabla$}

Prof. Dr. Hayes-Gill is employed by the University of Nottingham and is also a Director of Monica Healthcare Ltd.

\section{Affiliations}

${ }^{1}$ Obstetrics and Gynaecology Department, Johann Wolfgang Goethe University Frankfurt, Frankfurt

${ }^{2}$ School of Electrical and Electronic Engineering, University of Nottingham, Nottingham, United Kingdom

${ }^{3}$ Obstetrics and Gynaecology, Teaching Hospital of the Ruhr-University Bochum, Witten

${ }^{4}$ Deutsche Gesellschaft für Hypnose und Hypnotherapie, German Society for Clinical Hypnosis, Coesfeld

${ }^{5}$ Department of Biostatistics and Mathematical Models, Johann Wolfgang Goethe University Frankfurt am Main, Frankfurt

\section{References}

1 Revenstorf D. Expertise zur Beurteilung der wissenschaftlichen Evidenz des Psychotherapieverfahrens Hypnotherapie. Z Hypnose und Hypnotherapie 2006; 1: 7-164

2 Revenstorf $D$. Clinical hypnosis: theoretical and empirical state of the art. Psychother Psychosom Med psychol 1999; 45: 5-13

3 Rainville P, Hofbauer RK, Bushnell MC et al. Hypnosis modulates activity in brain structures involved in the regulation of consciousness. J Cogn Neurosci 2002; 14: 887-901

4 Maquet $P$, Faymonville ME, Degueldre $C$ et al. Functional neuroanatomy of hypnotic state. Biol Psychiatry 1999; 45: 327-333

5 DePascalis V, Penna PM. 40-Hz EEG activity during hypnotic induction and hypnotic testing. Int J Clin Exp Hypn 1990; 38: 125-138

6 DePascalis $V$, Perrone M. EEG asymmetry and heart rate during experience of hypnotic analgesia in high and low hypnotizables. Int J Psychophysiol 1996; 21: 163-175

7 Alexander B, Turnbull D, Cyna A. The effect of pregnancy on hypnotizability. Am J Clin Hypn 2009; 52: 13-22

8 Gruzelier JH. The role of psychological intervention in modulating aspects of immune function in relation to health and well-being. Int Rev Neurobiol 2002; 52: 383-417

9 Pinnell CM. Empirical findings on the use of hypnosis in medicine: a critical review. Int J Clin Exp Hypn 2000; 48: 170-194

10 Reinhard J, Hüsken-Janßen H, Hatzmann $\mathrm{H}$ et al. Hypnotherapie bei vorzeitiger Wehentätigkeit. Geburtsh Frauenheilk 2008; 68: 603-606

11 Reinhard J, Hüsken-Janßen H, Hatzmann $\mathrm{H}$ et al. Preterm labour and clinical hypnosis. Contemporary Hypnosis 2009; 26: 187-193

12 Reinhard J, Hüsken-Janßen H, Hatzmann H et al. Hypnotherapie, Gestationsalter und Frühgeburtenrate. Z Geburtsh Neonatol 2010; 214: 82-87

13 Reinhard J, Hüsken-Janßen H, Hatzmann $\mathrm{H}$ et al. Veränderung des Gefäßwiderstands der Arteria umbilicalis, der fetalen Bewegung und der Herzzeitvariation durch Hypnose - Erste Ergebnisse. Z Geburtsh Neonatol 2009; 213: 23-26

14 Whorwell PJ, Houghton LA, Taylo EE et al. Physiological effects of emotion: assessment via hypnosis. Lancet 1992; 340: 69-72

15 Calvert EL, Houghton LA, Cooper $P$ et al. Long-term improvement in functional dyspepsia using hypnotherapy. Gastroenterology 2002; 123: $1778-1785$

16 Gonsalkorale WM, Miller V, Afzal A et al. Long-term benefits of hypnotherapy for irritable bowel syndrome. Gut 2003; 52: 1623-1629
17 Von Hippel C, Hole G, Kaschka WP. Autonomic profile under hypnosis as assessed by heart rate variability and spectral analysis. Pharmacopsychiatry $2001 ; 34: 111-113$

18 Akselrod S, Gordon D, Ubel FA et al. Power spectrum analysis of heart rate fluctuation: a quantitative probe of beat-to-beat cardiovascular control. Science 1981; 213: 220-222

19 Malik M, Bigger JT, Camm AJ et al. Heart rate variability. Standards of measurement, physiological interpretation and clinical use. Circulation 1996; 93: 1043-1065

20 David M, Hirsch M, Karin J et al. An estimate of fetal autonomic state by time-frequency analysis of fetal heart rate variability. J Appl Physiol 2007; 102: 1057-1064

21 Van Leeuwen P, Geue D, Lange S et al. Changes in the frequency power spectrum of fetal heart rate in the course of pregnancy. Prenat Diagn 2003; 23: 909-916

22 Assali NS, Brinkman CR, Woods JR et al. Development of neurohumoral control of fetal, neonatal, and adult cardiovascular functions. Am J Obstet Gynecol 1977; 129: 748-759

23 Breborowicz G, Moczko J, Gadzinowski J. Quantification of the fetal heart rate variability by spectral analysis in growth-retarded foetuses. Gynecol Obstet Invest 1988; 25: 186-191

24 Reinhard J, Hüsken-Janßen H, Hatzmann H et al. Veränderung der mütterlichen und fetalen Herzrate durch Hypnotherapie. Suggestion 2009; 1: $8-17$

25 Reinhard J, Hayes-Gill BR, Yi Q et al. Signalqualität der nicht-invasiven fetalen Echokardiographie (EKG) unter der Geburt. Geburtsh Frauenheilk 2009; 69: 703-706

26 Reinhard J, Hayes-Gill BR, Yi Q et al. The equivalence of non-invasive foetal electrocardiogram (fECG) to Doppler cardiotocogram (CTG) ultrasound during the 1st stage of labour. J Perinat Med 2010; 38: 179185

27 Reinhard J, Hayes-Gill BR, Yi Q et al. Long term non-invasive fetal electrocardiogram (fECG) and Doppler cardiotocogram (CTG) ultrasound during 1st and 2nd stage of labor. J Perinat Med 2009; 37 (S1): 638

28 Barber TX, Wilson SC. The Barber suggestibility scale and the creative imagination scale: experimental and clinical applications. Am J Clin Hypn 1978-1979; 2-3: 84-108

29 Lorenz-Wallacher L. Schwangerschaft, Geburt und Hypnose: Selbsthypnosetraining in der Modernen Geburtsvorbereitung. Heidelberg: CarlAuer-Systeme Verlag; 2003

30 Task force of the European society of cardiology and the North American society of pacing and electrophysiology. Heart rate variability - standards of measurement, physiological interpretation, and clinical use. Circulation 1996; 93: 1043-1065

31 Beckers F, Ramaekers D, Aubert E. ACTS: automated calculation of tachograms. Prog Biom Res 1999; 4: 160-165

32 Chung DY, Sim YB, Park KT et al. Spectral analysis of fetal heart rate variability as a predictor of intrapartum fetal distress. Int J Gynacol Obstet 2001; 73: 109-116

33 Malliani A. Principles of cardiovascular neural Regulation in Health and Disease. Boston: Kluwer; 2000

34 Van Leeuwen P, Lange S, Bettermann $H$ et al. Fetal heart rate variability and complexity in the course of pregnancy. Early Hum Dev 1999; 54: 259-269

35 Emdin M, Santarcangelo E, Picano E et al. Hypnosis effect on RR interval and blood pressure variability. Clin Sci 1996; Suppl. 91: 36

36 Aubert AE, Verheyden B, Beckers $F$ et al. Cardiac autonomic regulation under hypnosis assessed by heart rate variability: Spectral analysis and fractal complexity. Neuropsych 2009; 60: 104-112

37 De Pascalis V, Ray WJ, Tranquillo I et al. EEG activity and heart rate during recall of emotional events in hypnosis: relationships with hypnotizability and suggestibility. Int J Psychophysiol 1998; 29: 255-275

38 Von Hipple C, Hole G, Kaschka P. Autonomic profile under hypnosis as assessed by heart rate variability and spectral analysis. Pharmacopsychiatry 2001 ; $34: 111-113$

39 Gemignani A, Santarcangelo E, Sebastiani L et al. Changes in autonomic and EEG patterns induced by hypnotic imagination of aversive stimuli in man. Brain Res Bull 2000; 53: 105-111

40 Schneider U, Schleussner E, Fiedler A et al. Fetal heart rate variability reveals differential dynamics in the intrauterine development of the sympathetic and parasympathetic branches of the autonomic nervous system. Physiol Meas 2009; 30: 215-226

41 Gerstner T, Sprenger J, Schaible T et al. Maturation of the autonomic nervous system: differences in heart rate variability at different gestational weeks. Z Geburtsh Neonatol 2010; 214: 11-14 
42 Van Woerden EE, van Geijn HP, Caron EJM et al. Spectral analysis of fetal heart rhythm in relation to fetal regular mouthing. Int J Biomed Comput 1990; 25: 253-260

43 Wakai RT, Wang M, Pedron SL et al. Spectral analysis of antepartum fetal heart rate variability from fetal magnetocardiogram recordings. Early Hum Dev 1993; 35: 15-24

44 Sakakibara M, Takeuchi S, Hayano J. Effect of relaxation training on cardiac parasympathetic tone. Psychophysiology 1994; 31: 223-228

45 DeBenedittis G, Cigada M, Bianchi A et al. Autonomic changes during hypnosis: a heart-rate-variability power spectrum analysis as a maker of sympatho-vagal balance. Int J Clin Exp Hypn 1994; 42: 140-152

46 Ray WJ, Sabsevitz D, De Pascalis Vet al. Cardiovascular reactivity during hypnosis and hypnotic susceptibility: three studies of heart rate variability. Int J Clin Exp Hypn 2000; 48: 22-31

47 Baglini R, Sesana M, Capuano C et al. Effect of hypnotic sedation during percutaneous transluminal coronary angioplasty on myocardial ischemia and cardiac sympathetic drive. Am J Cardiol 2004; 93: 1035-1038

48 Reinhard J, Hüsken-Janßen H, Schiermeier S. Hypnoreflexogene Methode der Geburtsvorbereitung nach Schauble. Z Geburtsh Neonatol 2007; 211: $162-164$
49 Beckers F, Verheyden B, Aubert AE. Aging and nonlinear heart rate control in a healthy population. Am J Physiol Heart Circ Physiol 2006; 290: $\mathrm{H} 2560-\mathrm{H} 2570$

50 Goldberger AL. Nonlinear dynamics, fractals and chaos: applications to cardiac electrophysiology. Ann Biomed Eng 1990; 18: 195-198

51 Goldberger AL, Amaral LAN, Hausdorff JM et al. Fractal dynamics in physiology: alterations with disease and aging. Proc Natl Acad Sci USA 2002; 99: 2466-2472

52 Beckers F, Verheyden B, Ramaekers $D$ et al. Effects of autonomic blockade on non-linear cardiovascular variability indices in rats. Clin Exp Pharmacol Physiol 2006; 33: 431-439

53 Mujica-Parodi LR, Yeragani V, Malaspina D. Nonlinear complexity and spectral analyses of heart rate variability in medicated and unmedicated patients with schizophrenia. Neuropsychobiology 2005; 51: $10-15$

54 Fleisher LA, Dipietro JA, Johnson TRB et al. Complementary and non-coincident increases in heart rate variability and irregularity during fetal development. Clin Sci 1997; 92: 345-349 